\title{
RELATO DE EXPERIÊNCIA DO USO DAS TDIC POR ALUNOS CHAMADOS DE NATIVOS DIGITAIS EM ESCOLA PÚBLICA ESTADUAL DE ENSINO MÉDIO EM RECIFE-PE
}

\section{EXPERIENCE REPORT ON THE USE OF TDIC BY SO-CALLED DIGITAL NATIVES IN A STATE PUBLIC HIGH SCHOOL IN RECIFE-PE}

\section{INFORME DE EXPERIENCIA DEL USO DE LAS TDIC POR PARTE DE LOS ALUMNOS DENOMINADOS NATIVOS DIGITALES EN EL INSTITUTO PÚBLICO ESTATAL DE RECIFE-PE}

Claudemir Jeremias de Lima ${ }^{1}$ Neiton Carvalho da Silva ${ }^{2}$ Elidiene Gomes de Oliveira Lima ${ }^{3}$ Gilberto Amado de Azevedo Cysneiros Filho ${ }^{4}$

Submetido em: 13/05/2021 - Aceito em: 28/09/2021 - Publicado em: 17/12/2021.

\footnotetext{
${ }^{1}$ Possui graduação em Sistemas de Informação - Faculdade Integrada do Recife - FIR (2007). Especialização em Educação à Distância - Universidade Castelo Branco Rio de Janeiro (2010). Especialização Mídias na Educação - Universidade Federal Rural de Pernambuco - UFRPE (2012). Mestrado em Informática Aplicada Universidade Federal Rural de Pernambuco - UFRPE (2020).

2 Possui graduação em Sistemas de Informação - UFRPE. Licenciatura em Computação - UFRPE. Especialização em Informática na Educação. Licenciatura em Matemática - FAEL. Mestrando em Informática Aplicada - UFRPE.

${ }^{3}$ Possui Licenciatura em Física pela Universidade Federal Rural de Pernambuco (2011). Tem Especialização em Tecnologia na Aprendizagem pelo Centro Universitário Senac de São Paulo na modalidade à distância. Possui Especialização em Coordenação Pedagógica pela Faculdade Frassinetti do Recife. Foi tutora a distância em metodologia na EAD - COLÉGIO AGRÍCOLA DOM AUGOSTINHO IKAS-CODAI-UFRPE no período de 2012 a 2015. É professor I polivalente da Prefeitura Municipal de Recife desde 2003. Mestranda do Programa de Pós-Graduação em Educação Matemática e Tecnológica, EDUMATEC, UFPE.

${ }^{4}$ Possui graduação em Ciência da Computação pela Universidade Federal de Pernambuco (1998), mestrado em Ciência da Computação pela Universidade Federal de Pernambuco (2001) e PhD in Computer Science pela City, University of London (2011) e fez pós-doutorado na The Open University (UK) em 2016. Atualmente é professor adjunto da Universidade Federal Rural de Pernambuco. Tem experiência na área de Ciência da Computação, com ênfase em Engenharia de Software, atuando principalmente nos seguintes temas: rastreamento de software, engenharia de requisitos, desenvolvimento de aplicações para dispositivos móveis e desenvolvimentos de aplicações para web. Outras áreas de interesse inclui: jogos sérios e Web VR.
} 


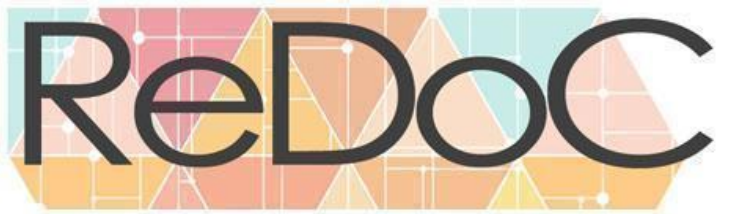

\section{Revista Docência e Cibercultura}

\section{RESUMO}

A utilização das tecnologias digitais de informação e comunicação (TDIC) têm sido cada vez mais presentes no ensino e aprendizagem. No entanto, os chamados nativos digitais nascidos e crescidos rodeados de tecnologia e mídias digitais podem sim, ter dificuldade de acessar informações e utilizar os dispositivos. A hipótese levantada neste trabalho é que, apesar de ser chamado de nativos digitais, há sim dificuldades para a utilização dos recursos tecnológicos (TDIC) pelos alunos em sala de aula das escolas públicas. Nesse sentido, essa pesquisa visa investigar as dificuldades dos estudantes na utilização dos recursos tecnológicos, computador desktop, buscando responder sobre os dispositivos tecnológicos mais utilizados, nível de conhecimento sobre os Aplicativos Office, utilização de jogos online comparado com os alunos que não jogam online. Para a verificação da pertinência dessa hipótese, realizou-se uma pesquisa documental, observação e pesquisa quantitativa de caráter descritivo com aplicação de questionário online e tabulação dos dados em uma Escola ETE da rede pública da região metropolitana do Recife. A principal contribuição desta pesquisa foi a identificação dos principais recursos tecnológicos mais utilizados pelos estudantes e a relação, identificada da utilização do computador para jogos online e a maior familiaridade com os recursos de hardware e softwares.

PALAVRAS-CHAVE: TDIC. Nativos digitais. BNCC. ETE.

\section{ABSTRACT}

The use of digital information and communication technologies (ICT) has been increasingly present in teaching and learning. However, the so-called digital natives, born and raised surrounded by technology and digital media, may have difficulty accessing information and using the devices. The hypothesis raised in this paper is that, despite being called digital natives, there is indeed difficulty in using technological resources (ICT) by students in the classroom of public schools. In this sense, this research aims to investigate the difficulties of students in the use of technological resources, desktop computer, seeking to answer about the most used technological devices, level of knowledge about Office Applications, use of online games compared to students who do not play online. In order to verify the relevance of this hypothesis, a documental research, observation and quantitative research of descriptive character was carried out with the application of an online questionnaire and data tabulation in a public school in the metropolitan region of Recife. The main contribution of this research was the identification of the main technological resources most used by students and the relationship identified between the use of computers for online games and the greater familiarity with hardware and software resources.

KEYWORDS: DICT. Digital natives. BNCC. ETE.

\section{RESUMEN}

El uso de las tecnologías digitales de la información y la comunicación (TIC) está cada vez más presente en la enseñanza y el aprendizaje. Sin embargo, los llamados nativos digitales, que han nacido y crecido rodeados de tecnología y medios digitales, pueden tener dificultades para acceder a la información y utilizar los dispositivos. La hipótesis planteada en este trabajo es que, a pesar de ser llamados nativos digitales, existen dificultades en el uso de los recursos tecnológicos (TIC) por parte de los alumnos en el aula de los centros públicos. En este sentido, esta investigación pretende indagar sobre las dificultades de los alumnos en el uso de los recursos tecnológicos, el ordenador de sobremesa, buscando responder sobre los dispositivos tecnológicos más utilizados, el nivel de conocimiento sobre las aplicaciones de Office, el uso de juegos online en comparación con los alumnos que no juegan online. Para verificar la pertinencia de esta hipótesis, se realizó una investigación documental, de observación y cuantitativa de carácter descriptivo con aplicación de cuestionario online y tabulación de datos en una escuela pública de la región metropolitana de Recife. La principal contribución de esta investigación fue la identificación de los principales recursos tecnológicos más utilizados por los estudiantes y la relación identificada entre el uso del ordenador para los juegos en línea y la mayor familiaridad con los recursos de hardware y software.

PALABRAS CLAVE: TIC. Los nativos digitales. BNCC. ETE. 


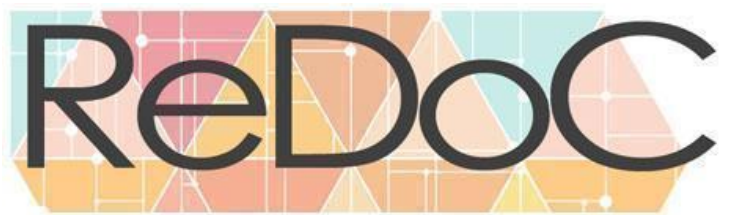

Revista Docência e Cibercultura

\section{INTRODUÇÃO}

Nas últimas décadas, as Tecnologias Digitais de Informação e Comunicação (também conhecida como TDIC) mudaram a maneira como trabalhamos, comunicamos, conectamos e aprendemos. Na educação, as TDIC foram incorporadas à prática de ensino para promover uma aprendizagem mais significativa e sendo assim, um importante instrumento de mediação (RABELLO, 2020). O objetivo é apoiar os professores na implementação de métodos de ensino ativos, tornar o processo de ensino consistente com a situação real dos alunos e despertar maior interesse dos alunos. Neste sentido, diversas políticas públicas foram implantadas ao longo dos anos com o objetivo de disseminar as tecnologias digitais para fins de ensino. Com o Programa Nacional de Informática Educacional (PROINFO) implantado pelo Ministério da Educação no final da década de 1990, diversas ações voltadas à capacitação de escolas e formação de professores foram se consolidando gradativamente (DE MELO et al. 2020).

Neste sentido, a Base Nacional Comum Curricular (BNCC) proporciona o desenvolvimento de competências e habilidades relacionadas com as tecnologias digitais essenciais e responsáveis de forma horizontal existentes em todas as áreas do conhecimento e destacando várias habilidades e competências com diferentes objetos de aprendizagem, de forma direcionada. Objetiva desenvolver habilidades relacionadas ao uso de tecnologias digitais, recursos e linguagens, isto é, habilidades usadas para desenvolver a compreensão, uso e criação da TDIC em várias práticas sociais.

A contemporaneidade é fortemente marcada pelo desenvolvimento tecnológico. Tanto a computação quanto às tecnologias digitais de informação e comunicação (TDIC) estão cada vez mais presentes na vida de todos, não somente nos escritórios ou nas escolas, mas nos nossos bolsos, nas cozinhas, nos automóveis, nas roupas etc. Além disso, grande parte das informações produzidas pela humanidade está armazenada digitalmente. Isso denota o quanto o mundo produtivo e o cotidiano estão sendo movidos por tecnologias digitais, situação que tende a se acentuar fortemente no futuro (BRASIL, 2017).

As TDIC fazem parte da vida das pessoas na sociedade atual e é fundamental que essa realidade seja refletida na escola. De forma que os alunos possam usufruir de seus benefícios e estejam preparados para enfrentar seus desafios (DOS SANTOS, 2021). Além disso, segundo González-Betancor (2021) existe uma necessidade de integração do uso das TDIC nas escolas como uma medida compensatória para desigualdades sociais de estudantes e pode contribuir para a redução da desigualdade digital.

A desigualdade digital refere-se às diferenças nos recursos materiais, culturais e cognitivos necessários para fazer bom uso das TIC. Tradicionalmente, as pesquisas sobre desigualdade digital têm se concentrado nas diferenças no acesso físico e na posse de ferramentas TIC, enfatizando que o acesso é apenas um dos muitos fatores necessários para se fazer bom uso da tecnologia (OCDE, 2015, p. 125). 
Nesse sentido, além dessas desigualdades sociais referente ao acesso e as habilidades necessárias para o uso das tecnologias, é preciso que os estudantes compreendam o processo de evolução das tecnologias na vida humana presente na sociedade da informação. Pinochet afirma que:

É importante conhecermos a história da informática para entendermos como evoluímos, onde estamos e para onde caminhamos com base na evolução de hardware, de software, e de redes, que favoreceram processos de evolução e revolução nas comunicações, e na forma como vivemos em um mundo em constantes transformações (PINOCHET, 2014, p. 89).

De acordo com a BNCC, a Cultura Digital envolve uma aprendizagem que visa participar de forma consciente e democrática por meio das tecnologias digitais, o que significa entender o impacto da revolução digital e do progresso da sociedade digital na sociedade contemporânea, bem como uma atitude crítica, ética e responsável em relação à construção da cultura. Está relacionado com a diversidade de mídias e produtos digitais, a possibilidade de uso de diferentes tecnologias e os conteúdos que veiculam, e se o uso das tecnologias digitais é fluente, e para expressar soluções e expressões culturais de forma contextual e crítica.

No Ensino Médio, por sua vez, dada a intrínseca relação entre as culturas juvenis e a cultura digital, torna-se imprescindível ampliar e aprofundar as aprendizagens construídas nas etapas anteriores. Afinal, os jovens estão dinamicamente inseridos na cultura digital, não somente como consumidores, mas se engajando cada vez mais como protagonistas. Portanto, na BNCC dessa etapa, o foco passa a estar no reconhecimento das potencialidades das tecnologias digitais para a realização de uma série de atividades relacionadas a todas as áreas do conhecimento, a diversas práticas sociais e ao mundo do trabalho (BRASIL, 2017, p.474).

Nesse contexto, sobre o reconhecimento das potencialidades das tecnologias digitais, a BNCC aponta competências e habilidades, nas diferentes áreas, que oportuniza aos estudantes:

Buscar dados e informações de forma crítica nas diferentes mídias, inclusive as sociais, analisando as vantagens do uso e da evolução da tecnologia na sociedade atual, como também seus riscos potenciais; Apropriar-se das linguagens da cultura digital, dos novos letramentos e dos multiletramentos para explorar e produzir conteúdo em diversas mídias, ampliando as possibilidades de acesso à ciência, à tecnologia, à cultura e ao trabalho (BRASIL, 2017, p.475).

Nesse caso, é preciso lembrar que a integração das tecnologias digitais na educação não é apenas utilizá-la como meio ou suporte para promover a aprendizagem ou despertar o interesse dos alunos, mas sim utilizá-la com os alunos para construir conhecimentos a ela relacionados. 


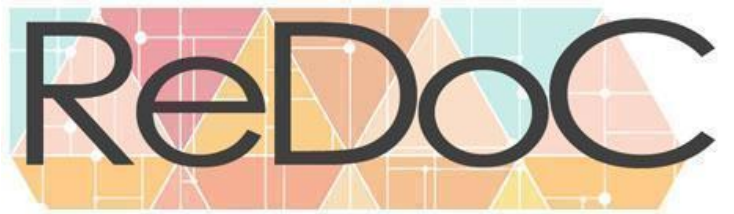

\section{Revista Docência e Cibercultura}

\section{FUNDAMENTAÇÃO TEÓRICA}

Os chamados nativos digitais nascidos e crescidos rodeados de tecnologia e mídia digital (aqueles que nasceram na sociedade tecnológica e estão familiarizados, desde muito cedo, com as linguagens dos meios digitais), não tem dificuldade de acessar informações, mas o risco é que muitas dessas informações são falsas, promovem ódio e são sensacionalistas. A maioria dos problemas potenciais são encontrados em várias telas e mídias sociais. (ALVES et al., 2020). Para Dantas et al. (2020) À medida que crianças e adolescentes usam as TDIC extensivamente, torna-se óbvio na sala de aula que eles estão equipados com dispositivos de tecnologia digital que trazem jogos e amplo acesso a redes sociais (como Instagram, Facebook e WhatsApp) para a sala de aula. Portanto, vale a pena refletir sobre que embora as tecnologias digitais tenham aumentado muito a capacidade de transmissão de informação e conhecimento, assistimos hoje a um aspecto dramático, ou seja, a distância entre quem tem acesso à tecnologia e pessoas que não podem usar essas tecnologias:

Se uma parcela dos novos alunos têm acesso à informação antes e fora da escola, apresentando tendência a sentirem-se desestimulados em sala de aula, uma outra parcela não tem sequer acesso à máquina e não sabe operar essa nova possibilidade. Estes alunos 'excluídos digitais', no entanto, têm notícia da existência da Internet e dos microcomputadores e desejam (e precisam mais que aqueles) conhecer novas modalidades de estudo, comunicação, lazer e cultura. (RIBEIRO e COSCARELLI, 2017, p. 9).

No entanto, para Alves et al. (2020) é importante destacar que embora as TDIC sejam muito fascinadas por crianças e jovens, devido ao processo de integração e utilização, esta geração de multimídia pode ainda não ser capaz de utilizar de forma plena e eficaz essas tecnologias. Essas tecnologias os recursos didáticos estão além do escopo da montagem do laboratório de informática. A introdução das TDIC na educação não está relacionada apenas às mudanças tecnológicas, mas também às mudanças sociais. Nesta conjuntura, é necessário criar um ambiente para a aprendizagem, em que os alunos possam construir seus conhecimentos em cooperação e interação com os professores.

As TDIC na educação podem ser usadas como uma ferramenta de trabalho, porque além da pesquisa científica, a educação também desempenha um papel importante em muitas indústrias técnicas e administrativas (PONTE, 2000). Novas tecnologias estão aqui, e são ferramentas que podem ser usadas livremente. As mais diferentes atividades são realizadas de forma criativa por professores e alunos. Dessa forma, os professores estão estimulando e promovendo a relação com a cognição, sugerindo aos alunos como construir a informação por meio da tecnologia, o que pode levar a conhecimento.

Já para Laurindo et al. (2020), vivemos um momento de mudanças drásticas na 
educação, os alunos impacientes não conseguem focar suas energias na construção de conhecimentos relevantes e, diante de todas essas inovações tecnológicas, os professores precisam aprender novas habilidades pedagógicas para acompanhar o processo cognitivo. Dado que o mundo está passando por todas essas transformações de avanços exponenciais em termos de acesso à informação, principalmente no processo de ensino, o uso das TDIC em sala de aula é um tema muito importante.

Segundo Do Nascimento (2020) o desenho da TDIC está diretamente relacionado ao desenvolvimento dos modernos sistemas de transmissão e informação em 1970, que deram origem à sociedade da informação. Nesse caso, inseriu-se o surgimento da Internet, utilizando uma série de mudanças na sociedade moderna ocorridas por volta da década de 1960 com a Guerra Fria como panorama histórico. O objetivo era estabelecer uma rede de comunicação altamente resistente que pudesse transmitir informações entre os diferentes centros militares dos EUA.

\section{METODOLOGIA}

Este artigo apresenta dados de uma pesquisa realizada em uma escola estadual e que visa a contribuir para a construção de conhecimento acerca das habilidades com o uso de computador tipo desktop. A pesquisa enfoca o contexto de estudantes do nível médio técnico e propõe a participação de estudantes do primeiro ano. Assim, o objetivo da pesquisa é investigar junto aos estudantes se há dificuldade na utilização do computador do laboratório de informática e elaborar uma estratégia para suprir estas deficiências na utilização destes recursos tecnológicos.

Neste artigo, investigamos as dificuldades dos estudantes na utilização dos recursos tecnológicos, computador desktop, buscando responder às seguintes perguntas:

1) Quais os dispositivos tecnológicos os estudantes possuem mais facilidades para utilizar?

2) Sob a perspectiva dos estudantes, qual o nível de conhecimento sobre os Aplicativos Office: editor de texto, planilha eletrônica, apresentação (Word, Excel, Power Point)?

3) Os alunos que participam de jogos online possuem mais conhecimento de hardwares e softwares quando comparado com os alunos que não jogam online?

Esta pesquisa é caracterizada como um estudo de caso descritivo Robert et al. (2001), visto que busca uma investigação profunda do grupo de alunos participantes, além da 
interpretação das respostas coletadas pelo questionário respondido. Os participantes do estudo são formados por 48 estudantes do curso médio técnico do primeiro ano, realizado durante o primeiro semestre de 2021.

O instrumento utilizado para a coleta dos dados e geração de gráficos foi um questionário utilizando o Google Forms e um software de planilha eletrônica para a formatação dos dados e gerar gráficos específicos. Este questionário foi aplicado por envio do link no Google Class. Após cada aluno ligar o computador nos primeiros dias de aulas presenciais do ano letivo de 2020, nos laboratórios de informática da escola, eles vivenciaram as dificuldades ou limitações para utilizar os recursos tecnológicos.

\section{RESULTADOS}

Nesta seção, apresentaremos e discutiremos os dados gerados na ferramenta para responder às três questões de pesquisa acima.

A primeira questão é, "Quais os dispositivos tecnológicos os estudantes possuem mais facilidades para utilizar?”. Procurou-se investigar a familiaridade com três recursos tecnológicos (celular, computador, tablet). Para isto, utilizamos os gráficos gerados pelo Google Forms que disponibiliza as respostas de cada aluno. O Gráfico 1, representa as respostas dos alunos.

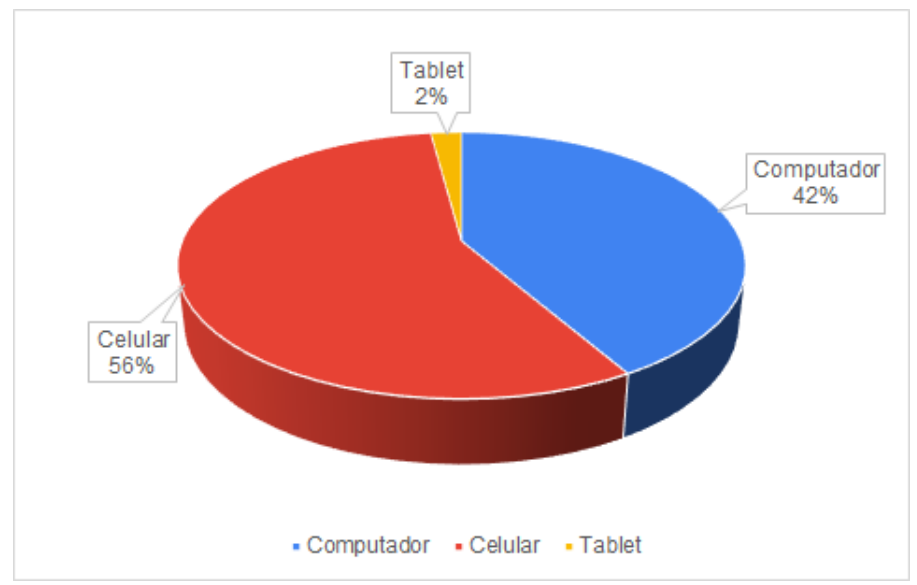

Gráfico 1. O aluno tem mais facilidade de usar.

Fonte: o autor desta pesquisa.

Cada aluno deveria escolher somente um destes recursos tecnológicos listados e só poderiam finalizar o questionário se todas as perguntas fossem respondidas. Durante as observações no dia a dia e no laboratório de informática o Gráfico 1 comprova que (56\% dos 
estudantes) que corresponde a 27 alunos têm mais familiaridade com a utilização dos celulares. Conforme evidenciado nas respostas das 48 respostas, apenas 20 alunos que correspondem a $42 \%$ possuem familiaridade com o uso dos computadores, em especial do tipo Desktop. Também quando se refere ao uso do tablet $2 \%$ das respostas afirmaram que possuem familiaridade com esta categoria de dispositivo, que corresponde a uma resposta.

Quadro 1. Familiaridade com os recursos tecnológicos

\begin{tabular}{|c|c|c|}
\hline Respostas & Dispositivo & Percentual distribuído \\
\hline 20 & Computador & $42 \%$ \\
\hline 27 & Celular & $56 \%$ \\
\hline 1 & Tablet & $2 \%$ \\
\hline
\end{tabular}

Fonte: o autor desta pesquisa

O Quadro 1 possibilita uma visão do número de respostas por tipo de recurso tecnológico que cada estudante possui mais familiaridade na utilização. Dessa forma, concordamos com os autores (RIBEIRO e COSCARELLI, 2017, p. 9) em sua pesquisa evidenciaram que uma parte nem consegue acessar o computador e não sabe como operar. Esse fato também entra em concordância com Alves et al. (2020) quando fala que essa geração multimídia pode ainda não ser capaz de utilizar de forma plena e eficaz essas tecnologias. Nesse sentido, o Quadro 1 confirma que a menor habilidade é com o tablet e computador. Talvez pelo fato de ser dispositivo menos utilizados em seu cotidiano, pois muitos não têm acesso a esses dispositivos em seus lares, e é na escola que os estudantes têm a oportunidades de vivenciar o uso de tais dispositivos como o computador e tablet, já que o uso dos celulares é mais comum em seu dia a dia. Nesse sentido, podemos trazer González-Betancor (2021), quando cita sobre a necessidade de integração do uso das TDIC nas escolas para contribuir para a redução da desigualdade digital.

Seguindo com esta pesquisa, perguntamos: Sob a perspectiva dos estudantes, qual o nível de conhecimento sobre os Aplicativos Office: Editor de texto, planilha eletrônica, apresentação (Word, Excel, Power Point)? O Gráfico 2 a seguir representa as respostas dos alunos. 


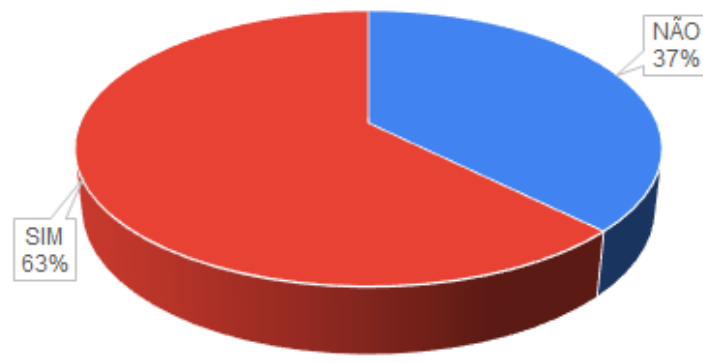

- NÃO $\cdot$ SIM

Gráfico 2. O aluno sabe usar os aplicativos Office.

Fonte: o autor desta pesquisa.

Utilizando o mesmo tipo de escolha, foi configurado que cada aluno deveria escolher somente uma opção sim ou não e só poderiam finalizar o questionário se todas as perguntas fossem respondidas. Durante as aulas com a utilização do computador do laboratório de informática, observamos que alguns alunos apresentaram algum tipo de adversidade para a elaboração de um documento, como a formatação e inserção de imagens. O Gráfico 2 evidencia que (37\% dos estudantes), que corresponde a 18 alunos dos 48, não sabiam utilizar algum dos aplicativos do pacote office, como por exemplo: editor de texto, planilha eletrônica e criar apresentação.

Das 48 respostas, 30 alunos que correspondem a 63\% sabiam utilizar algum dos softwares do pacote office. Sendo assim, conforme evidenciado na Figura 2 e identificado, há sim alunos que não tem habilidade na utilização destes recursos de software, que impossibilitaria a execução de atividades no computador para construção de documentos e cálculos com a utilização de planilha eletrônica. Nesse sentido, outra vez concordamos com Ribeiro e Coscarelli (2017, p. 9) e Alves et al. (2020), confirmando que há jovens que não possuem habilidades, ou acesso a dispositivos como o computador para operar de forma plena e eficaz com tais recursos digitais.

Para responder ao seguinte questionamento: os alunos que participam de jogos online possuem mais conhecimento de hardwares e softwares quando comparado com os alunos que não jogam online? Utilizamos as respostas coletadas no questionário. Para um maior entendimento do conhecimento do aluno sobre suas habilidades com os hardwares e softwares, perguntamos também aos alunos: Você utiliza jogos online no computador? Você sabe o que é Sistema Operacional? Você conhece as teclas de atalho do teclado do computador?

Inicialmente, separamos as respostas dos alunos que responderam sim, na pergunta sobre a utilização de jogos online no computador e em seguida montamos dois quadros com os 
que jogam e os que não jogam utilizando o computador.

O Gráfico 3 a seguir representa as respostas dos alunos sobre a utilização do computador para jogos online.

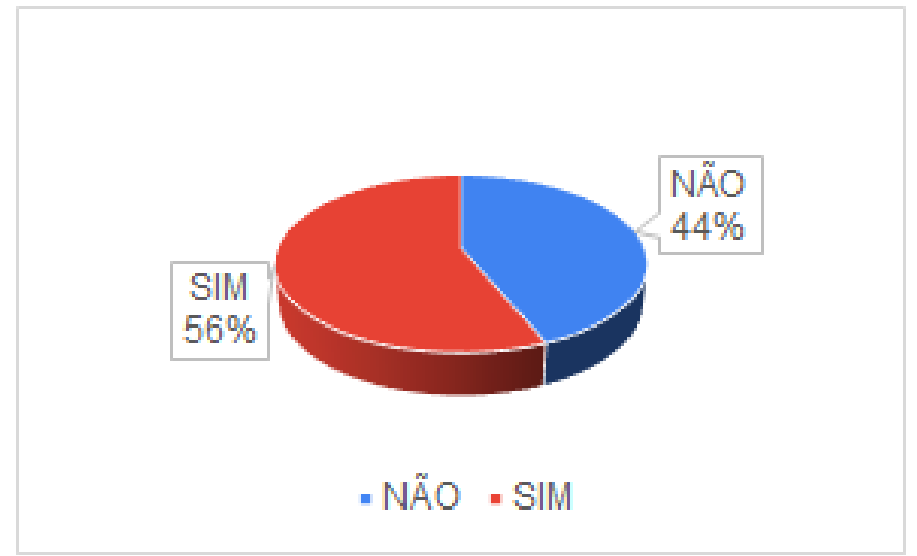

Gráfico 3. Utiliza o computador para jogos online.

Fonte: $\mathrm{o}$ autor desta pesquisa.

Com as respostas dos alunos, evidenciamos $56 \%$ que corresponde a 27 alunos utilizando o computador para jogos online. Sendo que 44\% (21 alunos) não jogam utilizando o computador. Partindo desta evidência, fizemos a separação em dois grupos: dos alunos que utilizam o computador para jogos online e dos que não jogam utilizando o computador. Para melhor entendimento separamos em dois Quadros.

A seguir, vamos analisar as respostas dos alunos que responderam sim, quando perguntado sobre utilizar jogos online no computador que corresponde a 27 alunos, as respostas estão apresentadas no Quadro 2.

Quadro 2. Alunos que participam de jogos online

\begin{tabular}{|c|c|c|}
\hline Respostas & $\begin{array}{c}\text { Você sabe o que é } \\
\text { Sistema Operacional? }\end{array}$ & $\begin{array}{c}\text { Você conhece as teclas de } \\
\text { atalho do teclado do } \\
\text { computador? }\end{array}$ \\
\hline SIM & 18 & 21 \\
\hline NÃO & 9 & 6 \\
\hline
\end{tabular}

Fonte: o autor desta pesquisa

A resposta sobre o conhecimento de software, perguntamos: Você sabe o que é Sistema Operacional? Evidenciamos que 18 alunos representando $38 \%$ dos alunos sabem a finalidade do sistema operacional, isso se confirma pela necessidade de instalação de drivers e softwares para utilização nos jogos online pelo computador. E sobre hardware 21 alunos representando 


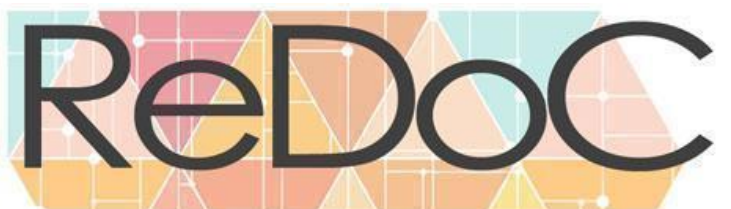

\section{Revista Docência e Cibercultura}

$44 \%$ dos alunos possuem conhecimento sobre os atalhos do teclado do computador também pelo fato do uso de tais teclas para jogos online com esse dispositivo. Nove alunos (19\% do total) responderam não quando perguntado sobre o sistema operacional e apenas 6 alunos que representam $13 \%$ não conhecem as teclas de atalhos do teclado do computador.

Contudo, fazendo uma análise apenas do quantitativo que participam de jogos online no computador, observamos que cerca de 67\% sabem o que é Sistema Operacional e aproximadamente $77,8 \%$, apresentando uma aumento significativo das habilidades e conhecimento com esse tipo de dispositivo para ter acesso às TDIC.

Quadro 3. Alunos que não participam de jogos online

\begin{tabular}{|c|c|c|}
\hline Respostas & $\begin{array}{c}\text { Você sabe o que é } \\
\text { Sistema Operacional? }\end{array}$ & $\begin{array}{c}\text { Você conhece as teclas de } \\
\text { atalho do teclado do } \\
\text { computador? }\end{array}$ \\
\hline SIM & 5 & 8 \\
\hline NÃO & 16 & 13 \\
\hline
\end{tabular}

Fonte: o autor desta pesquisa

No Quadro 3, evidenciamos que os alunos que responderam não utilizar o computador para jogos online, apresentam um menor conhecimento sobre o sistema operacional $10 \%$ dos alunos, representa 5 respostas e 33\% que equivale a 16 alunos que não têm conhecimento sobre o sistema operacional. E sobre as teclas de atalho apenas 8 alunos (17\%) responderam sim, sobre o que é sistema operacional e 13 alunos (27\%) que responderam não conhecem as teclas de atalho do computador.

Podemos destacar aqui duas questões, a de condições de acesso a esses dispositivos e dos diferentes de interesses relacionados à diversidade de mídias e produtos digitais como os jogos online em rede e produção de vídeos sobre os mesmos, por exemplo. Assim trazemos sobre a questão de González-Betancor (2021), quando cita que a escola pode contribuir para a redução da desigualdade digital.

Dessa forma concordamos que a escola deve aproveitar e oportunizar a apropriação das linguagens da cultura digital, dos novos letramentos e dos multiletramentos para ampliar as possibilidades de acesso aos estudantes para construção do conhecimento e conteúdo de forma protagonista em relação à ciência, à tecnologia, à cultura digital e ao trabalho (BRASIL, 2017).

Assim, trazemos para essa discussão Dantas et al. (2020), que afirma que torna-se óbvio que à medida que os estudantes estão inseridos na cultura digital eles apresentam maior familiaridade com o uso das TDIC nas salas de aula. Contudo, sabemos que há possibilidades do não acesso a esses dispositivos ou mesmo ao não uso de forma eficaz para construção de conhecimento, pois nem todos os sujeitos dessa pesquisa conseguem ter acesso ao computador ou não sabem como operar. É como afirma a BNCC que “os jovens estão dinamicamente inseridos na cultura digital, não somente como consumidores, mas se engajando cada vez mais como protagonistas." (BRASIL, 2017). 


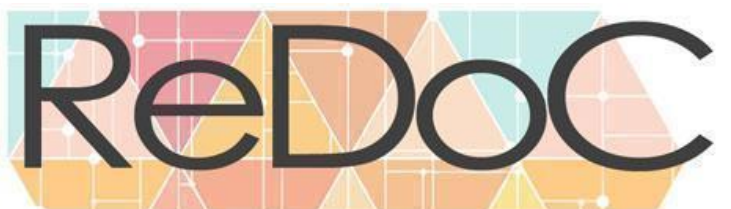

Revista Docência e Cibercultura

Dessa forma trazemos Pinochet $(2014$, p. 89) que afirma sobre a forma de como vivemos a cultura digital revelam para onde estamos e para onde caminhamos com base na evolução de hardware, de software, e de redes. Dessa forma, os dados revelaram que os estudantes que utilizavam os computadores para interação nos jogos online entre os pares influenciaram na familiaridade com o uso das tecnologias digitais disponíveis nesses dispositivos como aplicativos Office: Editor de texto, planilha eletrônica, apresentação (Word, Excel, Power Point, teclas de atalho e até mesmo sobre a consciência do que seria um Sistema operacional.

\section{CONSIDERAÇÕES FINAIS}

Consideramos que esta pesquisa contribuiu para evidenciar que estudantes chamados nativos digitais podem apresentar limitações na utilização das TDIC por meio do uso de dispositivos como computador desktop com seus aplicativos Office: Editor de texto, planilha eletrônica, Word, Excel, PowerPoint, entre outros conhecimentos como teclas de atalho ou mesmo o que seria um Sistema operacional.

Contudo, constatamos que os estudantes que utilizavam o computador como dispositivo para participar dos jogos online apresentaram maior habilidade e conhecimento com uso de computador assim como seus hardware e software. Sobretudo, verificamos que os estudantes apresentavam maior habilidades com o uso de celulares pelo fato de ser um dispositivos mais utilizado em diversas ações em seu cotidiano, mas não significando ter conhecimento e habilidade com o uso de computadores para acesso às TDIC.

Nesse sentido, destacamos duas questões nesta pesquisa, sobre as dificuldades com o uso de computadores desktop e seus demais recursos integrados, uma é sobre as possíveis limitações de acesso a esses dispositivos e a outra incide sobre os diferentes de interesses relacionados à diversidade de mídias e produtos digitais como na participação de jogos online evidenciada nesta pesquisa e à convergência dessas mídias, informações e conteúdo online presente no celular úteis para o seu cotidiano.

Dessa forma, concordamos que a escola deve aproveitar e oportunizar a apropriação das linguagens da cultura digital, dos novos letramentos e dos multiletramentos para promover as possibilidades de acesso aos estudantes para construção do conhecimento e conteúdo de forma protagonista em relação à ciência, à tecnologia, à cultura digital e ao trabalho. Assim, consideramos que a escola pode buscar ampliar e aprofundar as aprendizagens dos estudantes inseridos nessa cultura digital.

Contudo, quando falamos de cultura digital na educação, concordamos que envolve uma aprendizagem que visa a participação dos estudantes de forma mais consciente e democrática por meio das tecnologias digitais, o que significa entender o impacto e a importância da revolução digital e dos seus avanços na sociedade da informação para 
construção de conhecimento promovidos nas escolas.

\section{AGRADECIMENTOS}

O presente trabalho foi realizado com apoio do CNPq, FACEPE, CAPES e da UFRPE.

\section{REFERÊNCIAS}

ALVES, Gleissel Florisbelo et al. A percepção do uso das TDICs por professores em escolas públicas estaduais de ensino médio em Uberlândia/MG. 2020. http://doi.org/10.14393/ufu.di.2020.749

BRASIL, M. E. C. Base nacional comum curricular. Brasília-DF: MEC, Secretaria de Educação Básica, 2017. Disponível em: http://basenacionalcomum.mec.gov.br/abase/\#medio. Acesso em: 03 abril. 2021.

BRASIL. Ministério da Educação. Tecnologias Digitais da Informação e Comunicação no contexto escolar: possibilidades. Brasília, DF: MEC, 2018. Disponível em: http://basenacionalcomum.mec.gov.br/implementacao/praticas/caderno-depraticas/aprofundamentos/193-tecnologias-digitais-da-informacao-e-comunicacao-nocontexto-escolar-possibilidades?highlight=WyJocSJd. Acesso em: 03 abril. 2021.

DANTAS, Dina Mara Pinheiro et al. O descompasso da sala de aula e as Tecnologias Digitais. Research, Society and Development, v. 9, n. 11, p. e79691110416-e79691110416, 2020. https://doi.org/10.33448/rsd-v9i11.10416 
DE MELO, Maria Emília Ferraz Almeida; SOARES, Félix Alexandre Antunes; DE OMENA, Cristhiane Maria Bazílio. O COMPUTADOR E O RENDIMENTO ESCOLAR: UMA ANÁLISE SITUACIONAL COM CONCLUINTES DO ENSINO MÉDIO. Revista de Educação da Universidade Federal do Vale do São Francisco, v. 10, n. 21, p. 323-353, 2020. Disponível em: https://periodicos.univasf.edu.br/index.php/revasf/article/view/112. Acesso em: 03 abril. 2021.

DO NASCIMENTO, Regina Célia Ramos. AS TECNOLOGIAS DIGITAIS NO ENSINO DAS ARTES VISUAIS, 2020. Disponível em: http://www.editorarealize.com.br/editora/anais/conedu/2020/TRABALHO_EV140_MD1_SA 19_ID1091_26062020160143.pdf. Acesso em: 03 abril. 2021.

DOS SANTOS, Jorge Alberto. DESAFIOS QUE OS ESTUDANTES NATIVOS DIGITAIS LEVAM PARA A ESCOLA: RELATOS DE PROFESSORES. Revista Ibero-Americana de Humanidades, Ciências e Educação, v. $\quad$ 7, $\quad$ n. $\quad$ 2, p. 23-23, 2021. https://doi.org/10.51891/rease.v7i2.602

LAURINDO, Anderson Pedro et al. Relato de experiência do uso das TDICs para produção de mídias no ensino fundamental. Horizontes-Revista de Educação, v. 8, n. 15, p. 363-379, 2020. https://doi.org/10.30612/hre.v8i15.10289

OCDE (ORGANIZACIÓN PARA LA COOPERACIÓN Y EL DESARROLLO ECONÓMICOS). Students, Computers and Learning: Making the Connection. 2015. https://doi.org/10.1787/9789264239555-en

PONTE, João Pedro da. Tecnologias de informação e comunicação na formação de professores: que desafios?. Revista Iberoamericana de educación, p. 63-90, 2000. Disponível em: http://hdl.handle.net/10451/3993

PINOCHET, Luis. Tecnologia da informação e comunicação. Elsevier Brasil, 2014. 
RABELLO, Cíntia Regina Lacerda. INTERCÂMBIO VIRTUAL: CONTRIBUIÇÕES PARA A APRENDIZAGEM DA LÍNGUA INGLESA DE ESTUDANTES DE LETRAS. Revista $\begin{array}{lllllllll}\text { Docência } & \text { e } & \text { Cibercultura, } & \text { v. } & 4, & \text { n. } & 3, & \text { p. } & 58-82,\end{array}$ https://doi.org/10.12957/redoc.2020.53886

RIBEIRO, Ana Elisa; COSCARELLI, Carla Viana. Letramento digital: aspectos sociais e possibilidades pedagógicas. Autêntica, 2017.

ROBERT, Y. I. N. et al. Estudo de caso: planejamento e métodos. Porto Alegre: Bookman, 2001.

Sara M. González-Betancor, Alexis J. López-Puig, M. Eugenia Cardenal, Digital inequality at home. The school as compensatory agent, Computers \& Education, Volume 168,2021,104195,ISSN 0360-1315, $\quad$ https://doi.org/10.1016/j.compedu.2021.104195. (https://www.sciencedirect.com/science/article/pii/S0360131521000725)

Este é um artigo de acesso aberto distribuído sob os termos da Licença Creative Commons Atribuição Não Comercial-Compartilha Igual (CC BY-NC- 4.0), que permite uso, distribuição e reprodução para fins não comerciais, com a citação dos autores e da fonte original e sob a mesma licença. 